\title{
Perception and Cognition. All Colors of the World: Metaphorization of Color
}

\author{
L. V. Knyshevytska
}

\author{
Chair of Foreign Languages, Faculty of Law and International Relations \\ Borys Grinchenko Kyiv University, Kyiv, Ukraine \\ Corresponding author. E-mail: 1.knyshevytska@kubg.edu.ua
}

Paper received 29.07.21; Accepted for publication 19.08.21.

\section{https://doi.org/10.31174/SEND-Ph2021-257IX75-08}

\begin{abstract}
The present study investigates relationship of conventional Russian color metaphors with a group of directly embodied basic colors and a group of colors of secondary embodiment for twelve color domains categories within the boundaries of one cognitive system. The tallying of the metaphor data allowed to sort all color metaphors into six groups based on the presence in the mapping as a source or target domain of a particular component (concrete objects, fabrics, materials, abstract, philosophical ideas, moral qualities, names of the animals, emotions, and embodied components. The results of the study suggest that color metaphors of the primary embodied color group were more numerous and more diverse in meanings and emotional implications than that of the secondary embodied color group. Many metaphors in all six color domains in the first group were embodied, while metaphors in only one group of colors were embodied for the second group. Finally, metaphors in the group of primary embodiment were equally diverse in mappings with that of the color metaphors in the group of secondary embodiment.
\end{abstract}

Keywords: Cognitive science, conception, perception, color categories, basic colors, secondary colors, color metaphors, primary embodiment, secondary embodiment, cultural universals, cross-cultural variation.

Introduction. Resent metaphor research has placed great emphasis on examining relationship between perception and conception, investigating the ways common for all human beings' perceptual biases: visual, olfactory, motor, physical, bodily, auditory, sensory. The main interest is to determine how embodied metaphorical concepts interact with specific linguistic and cultural models. From the position of cognitive science, color categories are not entirely in the realm of our metaphysical existence, in other words, colors are not out there in the world. Instead, perception of colors is a result of interaction of physical characteristics of our eye to perceive electromagnetic radiation of particular length, lighting conditions and neural processing that is taking place in our brain. Outside of this mechanism, colors, as we perceive them, do not exist. Discussing graded levels of embodiment in complex color perception mechanism, Berlin and Kay [1] differentiated between three pairs of primary pure basic colors (black and white, red and green, yellow and blue) and five secondary basic color categories (brown, purple, pink, orange and gray) obtained through secondary interaction of afore mentioned six pure primary basic colors.

Review of Literature. Metaphor research examines relationship between common human sensory-motor and perceptual experiences (visual, olfactory, motor, physical, bodily, auditory, sensory) and embodied metaphors that have unique and often distinct salience for any particular cultural system and might vary from language to language Yu [20], [21]; Quinn [18]; Ibarrexte-Atuzano [5]; Cienki [8]; Deignan [6].

As Lakoff [16] noted, many universal concepts that people are reasoning about have metaphorical basis where one concept is being understood in terms of the other. "A large proportion of our most commonplace thoughts makes use of an extensive but unconscious, system of metaphorical concepts, that is, concepts from a typically concrete realm of thought that are used to comprehend another, completely different domain" (p.301).

In addition, Lakoff and Johnson [14] and Lakoff [15] stated that embodied conceptual metaphors build up not only on physical and perceptual domains (our sensorymotor system) but include cultural knowledge biases as well. That is why every cognitive system in every language will be concurrent with particular cultural values, models, perceptual images and folk beliefs: "the most fundamental values in a culture will be concurrent with the metaphorical structure of the most fundamental concepts in the culture" (Lakoff and Johnson [14], p. 22).

Among various embodied concepts that "we live by" is the domain of color. Colors represent complex physical experiences by which all human beings perceive light waves of various frequencies. Cognitive research focused on various ways color perceptions are mapped onto linguistic categories (Berlin \& Kay [1], Lakoff [16]; Lakoff and Johnson [14]). Discussing a relationship between perception and conception, Lakoff and Johnson [16] observed that our conceptual system is perceptually embedded. From the position of cognitive science, colors are not entirely in the realm of our metaphysical existence, in other words, colors are not out there in the world. Instead, perception of colors is a result of interaction of physical characteristics of our eye (three types of color cones in our retinas) to perceive electromagnetic radiation of a particular length (short, medium and long), lighting conditions and neural processing that is taking place in our brain. Outside of this mechanism, colors, as we perceive them, do not exist (Lakoff, [15], p.56).

In addition, Lakoff \& Johnson [14] have observed that physical stimuli, in general, and color stimuli, in particular, are commonly metaphorically mapped onto abstract domains. Despite the existence of a large number of metaphorical universals in color domains that arise from common perceptual biases, and similar cultural models, cross-culturally, there is a great deal of variation involved in the way the mappings are formed and the emphases are made.

Several studies have investigated a relationship between chromatic color qualities and color metaphors within either English language cognitive system (Jacobs and Jacobs [9]) or across cultures taking either synchronic or diachronic approaches to the problem of color metaphors and culture ( Italian: Cacciari, Massironi \& Corradini [4], English: Jacobs, \& Jacobs [9]; Russian: Bakhilina [3] ; Grigoruk [7]; Kulinskaya [13]; Mulyar [17]). 
In addition, many studies have investigated various aspects of color categorization across cultures and languages (Byrne\& Hilbert [2]; Jameson [10]; Jameson [11], Roberson [19]) among which Berlin and Kay's [1] classic comprehensive investigation of color phenomenon takes a central place. The researchers studied color perception, evolution of color terms, color naming and mechanisms of color categorization across many languages and cultures (ninety-eight total) and laid out a theoretical and empirical foundation for various studies to come. Among many interesting ideas is their stance about the existence of two levels in the way human perceptual mechanisms process and interpret chromatic color qualities. They differentiated between three pairs of primary pure basic colors (black and white, red and green, yellow and blue) directly perceived and processed by a human eye and five secondary basic color categories (brown, purple, pink, orange and gray) obtained as hues through secondary interaction of afore mentioned six pure basic colors. These two levels will be further referred as two levels of embodiment and will serve as theoretical grounding for a present study of color categories and color metaphors. "It appears now that, although different languages encode in their vocabularies different numbers of basic color categories, a total universal inventory of exactly eleven basic color terms of any given language are always drawn. The eleven basic color categories are white, black, red, green, yellow, blue, brown, purple, pink, orange and grey" (p. 2). A basic color was defined as having four characteristics: 1)' it is monolexemic, its meaning is not predictable from the meaning of its parts', 2)' its signification is not included in that of any other color term', 3) 'its application must not be restricted to a narrow class of objects', 4)' it must be physiologically salient for informants' (p.6).

Though many cross-cultural studies have investigated separately color categories and metaphors with the color component, very few looked at the relationship between levels of embodiment of a color category and color metaphors in a corresponding color domain within one cognitive system.

Research Question. The present study takes up this question investigating relationship of conventional Russian color metaphors with a group of directly embodied basic colors and a group of colors of secondary embodiment for twelve color domains (Berlin and Kay's, 1969 classification of basic color categories). The group of primary embodiment included six colors: 'bely' white, 'cherny' black,' krasny' red, 'siniy' blue, 'zhelty' yellow and 'zeleny' green. A group of secondary, mixed basic colors consisted of five colors mentioned by Berlin and Kay in their general classification: 'oranzhevy' orange, 'fioletovy' purple, 'sery' gray, 'korichnevy' brown,'rozovy' pink with one additional color added to this group, 'goluboy' light blue (Russian separate secondary basic color category. To deliberately control for equal number of colors: six in each group of primary and secondary embodiment, two more colors in the data,' zolotoy' golden and 'serebryany' silver, important for Russian metaphorical system were left out of this study and are discussed in detail elsewhere.

The working hypothesis for this study is that primary and secondary levels of embodiment of the basic color categories have direct effect on human metaphorical cog- nizance of human gestalt experiences. This would be supported by the fact that color metaphors of the primary embodied color group (black, white, green, red, blue, yellow) would be 1) more numerous and frequent, 2) more diverse in meanings and emotional implications, 3) more diverse in mappings than that of the secondary embodied color group (light blue, pink, brown, orange, purple, gray).

Method. The participants for this study were fifty-six native Russian speakers of who 22 spoke Russian as their native language, 23 were bilingual in Russian and Ukrainian and 11 claimed Ukrainian as their native language. The participants either had higher education or were obtaining higher education at the moment of data collection. Six participants had advanced degrees. The age range of the surveyed group was maintained deliberately quite wide (from 17 to 65 years old) in order to have a large scope sample of conventional color metaphors and possibly register the changes in interpretations and uses of conventional color metaphors concurrent with sociopolitical, historical and cultural changes in a society in various generations. There are four age groups in the study: 1) $17-19$ (19 subjects), 2) 20-29 (27 subjects), 3) 30-39 (5 subjects), 4) 4-64 (5 subjects). Six subjects were males and 50 were females. They spoke a variety of languages other than native language (s) including English, German, Polish, Greek, Italian and French and visited or lived for some time in the following counties: Israel, Belorussia, Russia, Poland, Lithuania, Check Rep, France, Germany, England, Belgium, Hungary, Bulgaria Austria. This particular information might be important in accounting for the cases of transfer of certain metaphorical expressions from one language to the other. Conventional metaphors of color elicited from 56 participants and uses of color metaphors in a natural linguistic environment found in newspapers and magazines constituted the corpora of data for this study.

The present paper is a qualitative synchronic study that investigated the degrees in which primary and secondary levels of embodiment interacted with color metaphors for twelve color domains in Russian. The colors were divided into two groups based on primary and secondary embodiment principle (Berlin and Kay, [1].

The preliminary tallying of the metaphor data allowed to sort all color metaphors into six groups based on the presence in the mapping as a source or target domain of a particular component (concrete objects, fabrics, materials, abstract, philosophical ideas, moral qualities, names of the animals, emotions, and embodied components) as in the following six groups:

\section{Metaphorical color mapping onto emotional do- mains}

Durak krasnomu rad Red makes a fool happy. Insignificant things make a fool happy.

\section{Metaphorical color mappings onto animals}

belaya vorona 'white crow' equivalent of a 'black sheep'

3. Metaphorical color mappings onto human body parts derzhat $v$ chernom tele to mentally and physically abuse someone

siniy nos 'blue nose' Drankard

\section{Metaphorical color mapping onto abstract and phil- osophical domains}


oranzevaya revolutsiya orange revolution. Bloodless revolution (elections in Ukraine when democrats von).

5. Metaphorical color mappings onto objects, liquids, parts of clothing and fabric

Krasnorubashechnik Red shirt man. Russian nationalist

6. Metaphorical mapping onto human moral qualities

belaya sovest 'white conscience'. Clean, pure, innocent conscience.

Results and Discussion. The present study investigated relationship of conventional Russian color metaphors with a group of directly embodied basic colors and a group of colors of secondary embodiment for twelve color domains (Berlin and Kay's, [1] classification of basic color categories). The group of primary embodiment included six colors: 'bely' white, 'cherny' black,' krasny' red, 'siniy' blue, 'zhelty' yellow and 'zeleny' green. A group of secondary, mixed basic colors consisted of five colors mentioned by Berlin and Kay [1] in their general classification: 'oranzhevy' orange, 'fioletovy' purple, 'sery' gray, 'korichnevy' brown,'rozovy' pink with one additional color added to this group, 'goluboy' light blue (Russian separate secondary basic color category).

In the course of metaphor analysis it was found that color metaphors of the primary color group: black, white, green, red, blue, yellow were almost three times as frequent and more diverse in meanings and emotional implications than that of the secondary color group: light blue, pink, brown, orange, purple, gray. In addition, there was a significant difference in embodied metaphors for both groups: all six color domains in the group of primary group had embodied metaphors in contrast to only one color domain in the group of secondary embodiment. Thus, Berlin and Kay's [1] take on different effect that primary and secondary levels of embodiment have on color naming and color term evolution (primary basic colors appeared in languages earlier than that of the secondary basic color terms) could be extrapolated to the generalizations about metaphorical system within at least one language, Russian. Color terms of primary embodiment in Russian appeared much earlier than that of the colors of secondary embodiment, they have about three times as more conventional metaphors with these six color components that are very diverse in meanings, due to changing folk beliefs, cultural, political, historical images and myths associated with these colors.

However, there appears to be no empirically supported grounds to claim that primary and secondary embodiment has any effect whatsoever on diversity and nature of the mappings of the metaphors within both groups. Which source or target domain is more salient, gets mapped and why is culture specific. Thus, the groups of primary and secondary embodiment displayed absolutely the same quite wide diversity in mappings for both primary and secondary basic colors. The same six types of mappings were found in each group of colors despite the fact that the first group of metaphors is about three times as large as the second one.

1. Metaphorical color mapping onto emotional domains

2. Metaphorical color mappings onto animals

3. Metaphorical color mappings onto human body parts

4. Metaphorical color mapping onto abstract and philosophical domains

5. Metaphorical color mappings onto objects, liquids, parts of clothing and fabric

6. Metaphorical mapping onto human moral qualities

Conclusion. The present study allowed to make a generalization that the way the Russian cognitive system dissects the experiential phenomena of color is undoubtedly culture specific and unique like for any other language system due to unique historical, socio-cultural, perceptual and dialectical aspects, models, images and values. It is unlikely that other languages will have absolutely identical perceptual sensitivity towards chromatic and perceptual qualities of color or adhere the same negative and / or positive connotations in relation to these chromatic qualities in exactly the same color domains and in the same way. Finally, if this for any unlikely reason were possible, the peculiarities of mappings in color domains would still be culturally embedded and accessed by the majority of the native speakers on a subconscious level.

\section{REFERENCES}

1. Berlin, B. \& Kay, P. (1969). Basic Color Terms: Their Universality and Evolution. Berkeley: University of California Press.

2. Byrne, A. \& Hibbert, D.R. (2003). Color realism and color science. Behavioral and Brain Sciences, 26, 3-64.

3. Bakhalina, H.B. (1975). Istoriya Tsetooboznacheniy v Russkom Yazyke. [ History of Color Terms in Russian Language]. Akademiya Nauk SSSR, Institut Russkogo Yazika, Moscva: Nauka.

4. Cacciari, C., Massironi, Massironi, M. \& Corradini, P. (2004) When color names are used metaphorically: the role of linguistics and chromatic information. Metaphor and Symbol, 19(3), 169-190.

5. Cienki, A. (1999). Metaphors and culture models as profiles and bases. In R. W. Gibbs, Jr.\& G. J. Steen (Eds.), Metaphors in cognitive linguistics (189-203). Amsterdam: John Benjamins.

6. Deignan , A. (2003). Metaphorical expressions and culture. Metaphor and Symbol, 18, 255-271.

7. Grigoruk, S.I. (1998). Kolorystychna leksika v poezii G.P Derzhavina (u konteksti poetuchnogo moblennya epokhi). [Color lexis in Derzhavin's poetry in the poetic context of the

epoch]. Doctoral dissertation, National Academy of Science of Ukraine, Potebnya Linguistics Institute, Kiev, Ukraine, 1998. Dissertation Abstracts, Donetsk National University library, ab 35970.

8. Ibarrexte-AtuZano, I.(1993). Metaphorical mappings in the sense of smell. In R. W. Gibbs, Jr.\& G. J. Steen (Eds.), Metaphors in cognitive linguistics (29-45). Amsterdam: John Benjamins.

9. Jacobs, V. and Jacobs, W. (1958). The color blue: Its use as metaphor and symbol. American Speech, 33(1), 29-46.

10. Jameson, K.A. (2005, February). On the role of culture in color naming: Remarks on the articles of Paramei, Kay, Roberson, and Hardin on the topic of cognition, culture, and color experience. Cross Cultural Research,(39)1, 88-106.

11. Jameson , K.A. (2005, February) . Introductory remarks on cognition, culture and color experience. Cross Cultural Research,(39)1, 5-9.

12. Kovecses, Z. (2002). Metaphor: A practical introduction, (pp. 163-197). Oxford: Oxford University Press.

13. Kulinskaya, S.V. (2002). Tsetooboznacheniya: natsionalnoculturnye ocobennosti functsionirovaniya (na materiale frazeologii I hudozhestvennyh tekstov Russkogo I An- 
gliyskogo yazykov). [Color-terms: national and cultural peculiarities of functioning, on the material of phraseology and fiction texts in Russian and English languages]. Doctoral dissertation, Kubansky State University, Krasnodar, Ukraine, 2002, Dissertation Abstracts, Donetsk National University library, ab. 42339.

14. Lakoff, G. \& Johnson, M. (1980). Metaphors we live by. Chicago: University of Chicago Press.

Lakoff, G. (1987). Women, Fire, and Dangerous Things. Chicago and London: The university of Chicago press.

15. Lakoff, G. (1993). The contemporary theory of metaphor. In A. Ortony (Ed)., Metaphor and thought (202-251), Cambridge: Cambridge University Press.

16. Lakoff, G. \& Johnson, M. (1999). Philosophy in the flesh. The embodied mind and its challenge to Western thought. New York: Basic Books.

17. Mulyar, S. P. (2003). Kolorystichna semantyka v strukturi Rossiyskogo xydozhnyogo tekstu (mova poezii $70-80$ pokiv of XX ctolittya). [Color semantics in the structure of Russian fiction text (the language of poetry of 70-80 of the XX century]. Doctoral dissertation, Kiev National University, Ukraine 2003. Dissertation Abstracts, Donetsk National University library, ab 43715 .

18. Quinn, N. (1987). Convergent evidence for a cultural model of American marriage. In D. Holland \& N. Quinn (Eds.), Cultural models in language and thought. Cambridge: Cambridge University Press.

19. Roberson, D. (2005, February). Color categories are culturally diverse in cognition as well as in language. Cross Cultural Research, (39)1, 56-71.

20. Yu, N. (1995). Metaphorical expressions of anger and happiness in English and Chinese. Metaphor and Symbolic Activity, 10, 59-82.

21. Yu, N. (2003). Metaphor, body, and culture: The Chinese understanding of gall bladder and courage. Metaphor and Symbol, 18, 13-31. 